\title{
Extrathoracic cannulation of the left common carotid artery in thoracic aorta operations through a left thoracotomy: Preliminary experience in 26 patients
}

\author{
Eugenio Neri, $\mathrm{MD}^{\mathrm{a}}$ \\ Massimo Massetti, MD \\ Lucio Barabesi, DrPh ${ }^{\text {b }}$ \\ Giorgio Pula, MD \\ Rossana Tassi, MD ${ }^{\mathrm{c}}$ \\ Thomas Toscano, MD \\ Enrico Tucci, MD ${ }^{\mathrm{a}}$ \\ Antonio Benvenuti, MDa \\ Gianni Capannini, MD \\ Fabio Miraldi, MD ${ }^{\mathrm{d}}$ \\ Carlo Sassi, MDa
}

From the Istitutos di Chirurgia Cardiovascolare, Unita' Operativa di Chirurgia dell' Aorta Toracica, ${ }^{\mathrm{a}}$ Metodi Quantitativi, ${ }^{\mathrm{b}}$ and Neurofisiopatologia, ${ }^{\mathrm{c}}$ Universita' agli Studi di Siena, Siena, Italy, and the Istituto di Chirurgia del Cuore e dei Grossi Vasi, ${ }^{\mathrm{d}}$ Università degli Studi "La Sapienza," Rome, Italy.

Received for publication June 25, 2001; revisions requested Aug 20, 2001; revisions received Sept 26, 2001; accepted for publication Oct 16, 2001.

Address for reprints: Eugenio Neri, MD, Istituto di Chirurgia Cardiovascolare Universita' agli Studi di Siena, Policlinico le Scotte, Viale M. Bracci, 53100 Siena, Italy (E-mail: euxneri@tin.it or nerie@unisi.it).

J Thorac Cardiovasc Surg 2002;123:901-10

Copyright $\odot 2002$ by The American Association for Thoracic Surgery

0022-5223/2002 \$35.00+0 $\quad \mathbf{1 2 / 1 / 1 2 1 3 0 0}$ doi:10.1067/mtc.2002.121300
Background: In aortic operations performed through a left thoracotomy, which require total bypass and deep hypothermic circulatory arrest, femoral artery cannulation is commonly used for arterial perfusion. This route limits the time of safe circulatory arrest and is associated with the risks of retrograde embolization or, in the case of aortic dissection, malperfusion of the vital organs. To overcome these problems, we have used cannulation of the extrathoracic left common carotid artery to ensure a central a route of arterial perfusion in these operations. The preliminary results are presented.

Methods: Between December 1999 and April 2001, we used left common carotid artery cannulation in 26 operations on the thoracic aorta performed through a posterolateral thoracotomy with an open technique during deep hypothermic circulatory arrest. Institutional review board approval and informed consent were obtained. The indications included perforating atherosclerotic ulcer $(\mathrm{n}=5)$, chronic aortic aneurysm $(\mathrm{n}=9)$, acute type B aortic dissection $(\mathrm{n}=3)$, and chronic dissection of the thoracic aorta $(n=9)$. Transcranial Doppler ultrasonographic monitoring of both the right and left middle cerebral arteries was used to assess the adequacy of cerebral bihemispheric perfusion and to determine the differences in blood flow velocities throughout the procedure.

Results: Left common carotid artery cannulation was successful in all patients. All patients awoke from the operation, and none had cerebrovascular accidents. None died in the hospital, and complications related to carotid artery cannulation were not observed. None of the patients experienced postoperative paraplegia. In all patients transcranial Doppler monitoring indicated the absence of cerebral embolic phenomena throughout the entire procedure. Significant differences in middle cerebral artery flow velocities were observed at different phases of the procedures and between the right and left middle cerebral arteries during carotid cannulation and during selective cerebral perfusion. Nevertheless, the maximal drop of right middle cerebral artery blood velocity during selective perfusion through the left common carotid artery was within 50\% of the left middle cerebral artery velocity, indicating adequate bihemispheric perfusion.

Conclusions: In patients undergoing aortic operations through a left thoracotomy, extrathoracic left common carotid artery cannulation was a safe and effective means of providing proximal arterial inflow during cardiopulmonary bypass, which can be used to selectively perfuse the brain, as well as to prevent embolic phenomena in the arch vessels. 


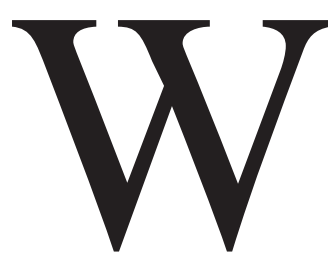

ith increasing frequency, hypothermic total cardiopulmonary bypass (CPB) with or without periods of circulatory arrest has been used for aortic reconstructions through a left thoracotomy. ${ }^{1,2}$

Although posterolateral thoracotomy provides a wide view of the distal aortic arch and descending aorta, central cannulation and selective cerebral perfusion may cause problems, especially in the presence of large aneurysms, which reduce the exposure of the proximal segments of the aorta. Furthermore, in these patients the ascending aorta and the proximal aortic arch are usually extremely fragile or affected by extensive calcifications, thereby exposing the patient to a high risk of bleeding and dissection at the cannulation site.

Femoral arterial perfusion is commonly used to achieve circulatory arrest. This procedure, however, is associated with a significant risk of emboli from atherosclerotic plaque or thrombi from the iliofemoral arterial wall and abdominal aortic wall being carried to either the brain or heart by means of retrograde perfusion. ${ }^{3,4}$ Femoral arterial perfusion can result in unsatisfactory perfusion to the proximal vital organs in cases of rupture, and malperfusion can occur in cases of aortic dissection. ${ }^{5}$ Moreover, when the open proximal method of repair is used during circulatory arrest, other problems may arise from femoral cannulation, including a restricted time of circulatory arrest to the brain and difficulties in deairing from the arch branches and the proximal ascending aorta.

In operations for distal arch and descending aortic conditions, we have adopted a method of cannulation of the extrathoracic left common carotid artery with the objective of providing antegrade cerebral perfusion to overcome these difficulties, which would allow prolongation of the time of safe circulatory arrest and could prevent embolic phenomena in the arch vessels.

\section{Patients and Methods \\ Patients}

Between December 22, 1999, and April 20, 2001, we used extrathoracic left common carotid artery cannulation in 26 consecutive operations (16 men and 10 women) on the thoracic aorta involving the distal aortic arch that were performed through a posterolateral thoracotomy with an open technique during deep hypothermic circulatory arrest (DHCA). The patients were informed about the risks and the advantages of the operative procedure, and written informed consent was obtained in all cases. Institutional review board approval for investigative procedures was obtained. The mean age of patients was 65.5 years (median, 66.5 years; range, 27-79 years). Patient characteristics are summarized in Table 1.

The indication for left common carotid artery cannulation was the repair of lesions of the thoracic aorta requiring deep hypothermia and circulatory arrest. The goal was to provide selective

\section{TABLE 1. Clinical characteristics of patients}

\begin{tabular}{|c|c|}
\hline Age (range), y & $65(27-79)$ \\
\hline Male/Female & $16 / 10$ \\
\hline Urgent surgery & $5(19.2 \%)$ \\
\hline Renal insufficiency & $2(7.6 \%)$ \\
\hline COPD & $4(15.3 \%)$ \\
\hline Hypertension & $24(92.3 \%)$ \\
\hline Previous cerebrovascular accident & $2(7.6 \%)$ \\
\hline CAD & $1(3.8 \%)$ \\
\hline Previous cardiac surgery & $1(3.8 \%)$ \\
\hline Smoking & $21(80.7 \%)$ \\
\hline Diabetes & $1(3.8 \%)$ \\
\hline Aortoiliac disease & $2(7.6 \%)$ \\
\hline AAA & $1(3.8 \%)$ \\
\hline \multicolumn{2}{|l|}{$\begin{array}{l}\text { Status of intracranial collateral pathways through } \\
\text { the anterior communicating artery }\end{array}$} \\
\hline Present & $16(61.5 \%)$ \\
\hline Absent & $9(34.6 \%)$ \\
\hline Not evaluated & $1(3.8 \%)$ \\
\hline \multicolumn{2}{|l|}{ Aortic pathology } \\
\hline $\begin{array}{l}\text { Perforating atherosclerotic ulcer of the } \\
\text { distal arch }\end{array}$ & $5(19.2 \%)$ \\
\hline Acute type B aortic dissection & $3(11.5 \%)$ \\
\hline Chronic dissection of the thoracic aorta & $9(34.6 \%)$ \\
\hline Fusiform chronic aortic aneurysm & $9(34.6 \%)$ \\
\hline \multicolumn{2}{|l|}{ Operation } \\
\hline Distal aortic arch replacement & $6(20.0 \%)$ \\
\hline $\begin{array}{l}\text { Distal aortic arch }+ \text { descending thoracic } \\
\text { aorta replacement }\end{array}$ & $18(69.3 \%)$ \\
\hline $\begin{array}{l}\text { Distal aortic arch + thoracoabdominal aorta } \\
\text { replacement }\end{array}$ & $2(7.6 \%)$ \\
\hline Left subclavian artery reimplantation & $14(53.8 \%)$ \\
\hline Left common carotid artery reimplantation & $1(3.8 \%)$ \\
\hline Visceral artery reimplantation & $2(7.6 \%)$ \\
\hline Intercostal/lumbar artery reimplantation & $20(76.9 \%)$ \\
\hline Associated carotid endarterectomy & $1(3.8 \%)$ \\
\hline CPB time (range), $\min$ & $168(122-235)$ \\
\hline $\begin{array}{l}\text { DHCA + selective cerebral perfusion time } \\
\text { (range), min }\end{array}$ & $31(18-52)$ \\
\hline
\end{tabular}

$C O P D$, Chronic obstructive pulmonary disease; $C A D$, coronary artery disease; $A A A$, abdominal aortic aneurysm.

cerebral perfusion and to facilitate the evacuation of air and debris from the arch vessel.

Left common carotid artery cannulation was successful in all patients. Concomitant femoral artery cannulation was performed in $24(92.3 \%)$ patients to ensure distal perfusion. Fourteen patients had atherosclerotic aneurysms, and of these, 9 were fusiform, involving part of the aortic arch and extending into the descending thoracic aorta in 7 patients. Five atherosclerotic aneurysms were saccular lesions consequent to perforating atherosclerotic ulcers with an entry point in the distal arch. The remaining 12 patients had acute $(n=3)$ or chronic $(n=9)$ aortic dissection that involved the arch and descending thoracic aorta. One of these patients had a chronic dissection and presented with a false aneurysm at the level of distal anastomosis of an ascending aortic graft implanted 3 years before for an acute type A aortic dissection. An emergency operation was required for a leaking aneurysm in 5 patients, 2 with acute type B dissection and 3 with ruptured atherosclerotic ulcers of the arch. 
TABLE 2. Preoperative investigations

\begin{tabular}{|c|c|c|c|}
\hline & Elective ( $\mathrm{n}=21$ ) & Urgent $(n=5)$ & Total $(n=26)$ \\
\hline Carotid duplex scan ultrasonography & $21(100 \%)$ & $3(60 \%)$ & $24(92 \%)$ \\
\hline Cerebral angiography & $21(100 \%)$ & 0 & $21(80 \%)$ \\
\hline $\begin{array}{l}\text { TCD ultrasonography with } \\
\text { compression maneuvers }\end{array}$ & $21(100 \%)$ & 0 & $21(80 \%)$ \\
\hline $\begin{array}{l}\text { Intraoperative TCD MCA flow } \\
\text { monitoring }\end{array}$ & $20(90 \%)$ & $5(100 \%)$ & $25(96 \%)$ \\
\hline $\begin{array}{l}\text { Intraoperative transesophageal } \\
\text { echocardiography }\end{array}$ & $21(100 \%)$ & $5(100 \%)$ & $26(100 \%)$ \\
\hline Preoperative cerebral MRI & $21(100 \%)$ & 0 & $21(80 \%)$ \\
\hline Postoperative cerebral MRI & $21(100 \%)$ & $5(100 \%)$ & $26(100 \%)$ \\
\hline Aortic angiography & $18(85 \%)$ & $2(40 \%)$ & $20(77 \%)$ \\
\hline Aortic CT scan & $21(100 \%)$ & $5(100 \%)$ & $26(100 \%)$ \\
\hline Abdominal aortic CT scan & $21(100 \%)$ & $5(100 \%)$ & $26(100 \%)$ \\
\hline Abdominal aortic ultrasonography & $21(100 \%)$ & $5(100 \%)$ & $26(100 \%)$ \\
\hline
\end{tabular}

Circulatory arrest was used in all patients. The mean period of cooling for these patients was 26 minutes. The time for rewarming averaged 44 minutes. Mean CPB time was 168 minutes (range, 122-235 minutes). The mean selective cerebral perfusion time was 31 minutes (range, 18-52 minutes). Concomitant carotid endarterectomy of the left carotid bifurcation was undertaken in 1 patient. Operations and operative variables are summarized in Table 1.

\section{Special Investigations}

Perioperative investigations are listed in Table 2.

All elective patients were referred to neurologists and underwent brain magnetic resonance imaging (MRI) scans in the preoperative period and after the operation. Urgent patients were given a general physical examination for their neurologic status before operation; they were referred to neurologists and underwent brain MRI scans in the postoperative period.

Preoperative duplex ultrasonography was obtained to rule out atherosclerotic lesions of extracranial carotid and vertebral vessels and to determine the optimal cannulation site in the left common carotid artery. Abdominal aorta duplex scans and contrast computed tomographic scans were evaluated to assess atherosclerotic lesions because these could indicate an absolute contraindication for concomitant femoral perfusion. Two patients presented with diffuse aortoiliac atherosclerotic lesions. Transcranial Doppler (TCD) monitoring and cerebral angiography with compression maneuvers were performed in all elective patients to assess activation of collateral pathways from the contralateral carotid artery. Blood velocity in the anterior, middle, and posterior cerebral arteries was quantified, and flow in the anterior and posterior communicating arteries was evaluated. ${ }^{6}$

Dissection of the aorta was not considered a contraindication to cerebral angiography. In 11 patients collateral blood flow through the circle of Willis was dependent on the anterior communicating artery and the ipsilateral posterior communicating artery, whereas in 9 patients the collateral circulation was dependent only on the posterior communicating artery.

In all urgent patients but one, with an absent temporal ultrasonic window, we monitored the functionality of intracranial collateral circulation by means of TCD monitoring only at the moment of the application of the common carotid artery clamp for cannulation. In this group all patients had functional intracranial collateral pathways through the anterior communicating artery and the ipsilateral posterior communicating artery.

Intraoperative TCD monitoring of the flow of both middle cerebral arteries (MCAs) was used in all patients but one, with an absent temporal ultrasonic window. During the operation, cerebral blood flow velocity was measured noninvasively with a $2-\mathrm{MHz}$, range-gated, pulsed-wave TCD ultrasonographic probe that was placed over the left and right temporal windows (EME TCD-2-64, Überlingen, Germany). ${ }^{7}$ Criteria for identification of various intracranial vessels were depth and direction of the signals, direction of the probe, characteristic pattern of the signal, and response to proximal common carotid and vertebral artery compressions.

The cerebral blood flow velocity was measured in the M1 segment of the MCA at critical phases of the procedure. The time points of the study were as follows: T1, basal; T2, left common carotid cannulation; $\mathrm{T} 3$, before $\mathrm{CPB}$; $\mathrm{T} 4$, normothermic $\mathrm{CPB}$; $\mathrm{T} 5$, hypothermic CPB; T6, DHCA with selective cerebral perfusion; T7, total CPB after DHCA; and T8, end of CPB.

To ensure a reproducible window, we aimed the probe so that the MCA signal was accompanied with a retrograde flow signal from the A1 segment of the anterior cerebral artery. Once an acceptable waveform was achieved, the probe position was secured with a holder, and care was taken not to dislodge the probe. Emboli were identified by their short duration, characteristic signal, and amplitudes greater than or equal to $10 \mathrm{~dB}$ from the background Doppler signal. ${ }^{8}$ Intraoperative transesophageal echocardiography was used in all patients.

\section{Operative Technique}

The patient was placed in the right decubitus position for posterolateral thoracotomy, with the chest and shoulders elevated $70^{\circ}$ (Figure 1, A). The torso was twisted back to allow the hips to lie as close to horizontal as possible. The left arm was elevated above the head and turned backward away from the neck; the head was rotated toward the right and extended. The groin and the left cervical region were included in the surgical field. A double-lumen endotracheal tube was used to facilitate collapse of the left lung. Arterial pressure-monitoring lines were placed in a femoral artery and in the right radial artery. Thoracotomy was performed through 

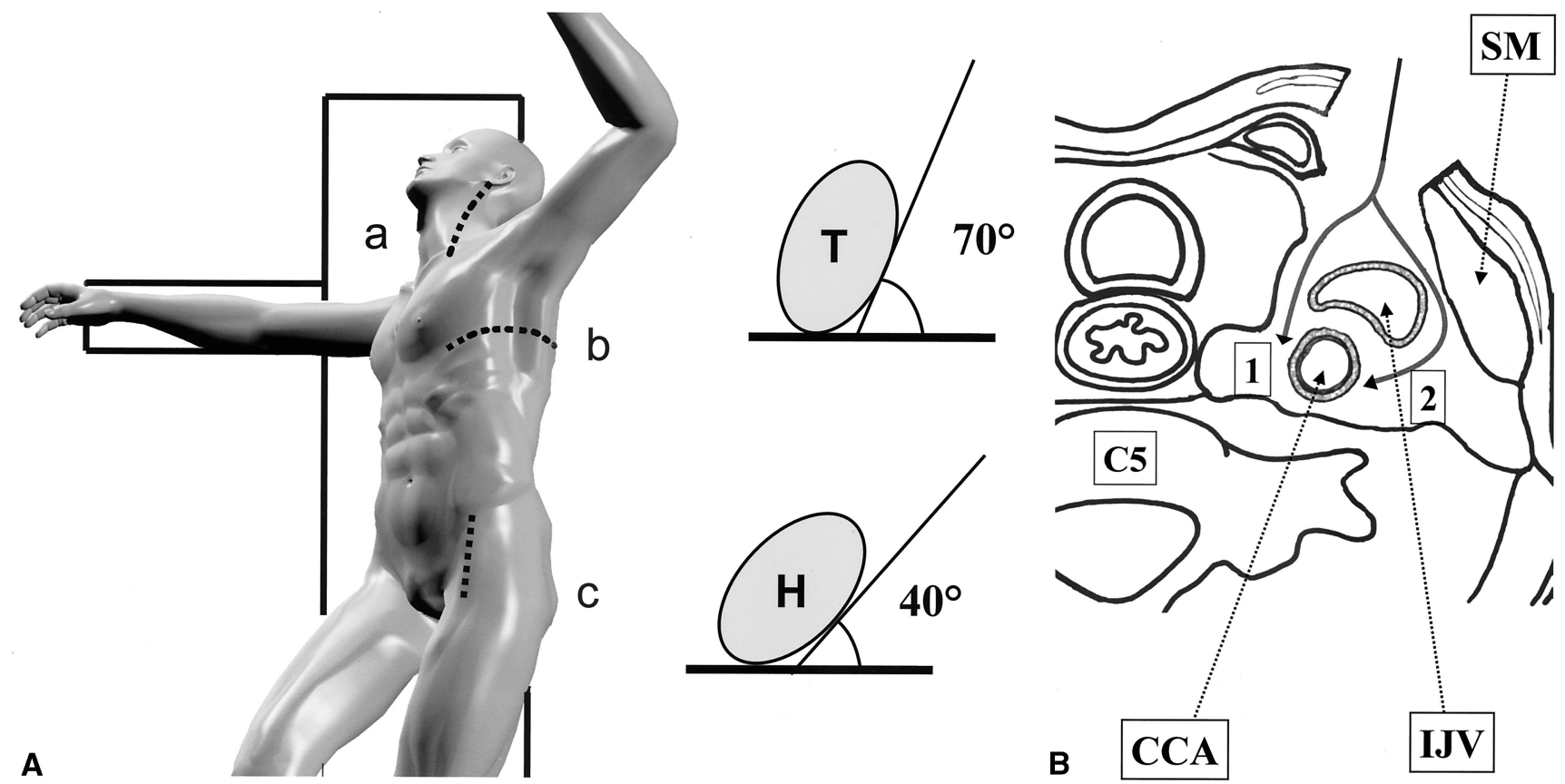

Figure $1 A$, The diagram illustrates the patient position on the table, with the laterocervical region exposed. Dotted lines indicate the sites of incision. The patient lies in a right decubitus position, with the chest (T) elevated about $70^{\circ}$ and the hips $(H)$ as close to horizontal as possible. The left arm is elevated above the head and turned backward away from the neck; the head is rotated toward the right and extended. $B$, Cross-section of the neck at the level of C5. The arrows indicate the 2 alternative approaches to the common carotid artery: medial (1) and retrojugular (2). CCA, Common carotid artery; IJV, internal jugular vein; SM, sternocleidomastoid muscle.

the fourth intercostal space. When the aortic pathologic condition extended to the diaphragm, the fifth rib was routinely excised to increase exposure. For thoracoabdominal replacement, a second incision was used through the seventh intercostal space. The left femoral artery and vein were exposed in the usual manner, and at the same time, the left common carotid artery was approached. An oblique incision was made along the medial margin of the sternocleidomastoid muscle, roughly the lower two thirds of the distance from its insertion and its origin. Once the skin, the subcutaneous tissue, and the platysma had been incised, the external jugular vein was often encountered and ligated. The incision was then deepened directly in front of the sternocleidomastoid muscle for the length of the incision, allowing exposure of the internal jugular vein. To gain access to the common carotid artery, there are 2 options (Figure 1,B): we can proceed in front (medial approach) to the jugular vein, or alternatively, we can encircle it laterally (retrojugular approach). In general we preferred a retrojugular approach, which is routinely used in carotid endarterectomy procedures. This route allowed us to stay away from the lymphatic tissue that lies above the carotid artery and to not divide the anterior facial vein, which drains in the medial aspect of the internal jugular vein. In both cases, either the medial or the retrojugular route, dissection was made in the cleft between the vein and the artery. The common carotid artery was encountered beside the vein in the soft areolar tissue surrounding both structures. For a wider proximal exposure, the omohyoid muscle, lifted up with a right-angle clamp, was transected by using cautery. By using the retrojugular route, small veins were encountered and divided, and the jugular vein was surrounded with 2 umbilical tapes and retracted medially, thus providing optimal exposure of the artery. Heparin was administered, and the cardiopulmonary circuit was set up. The left common carotid artery was crossclamped, and an 8-mm polytetrafluoroethylene graft (Sulzer-Vascutek Seal PTFE, Inchinnan, United Kingdom) of $20 \mathrm{~cm}$ in length was anastomosed end to side to the vessel. The graft was then cannulated with a $22 \mathrm{~F}$ cannula $(3 \mathrm{M} /$ Sarns, Ann Arbor, Mich) and connected to a side branch of the arterial line after careful deairing. An additional pressure-monitoring line was connected to the left common carotid cannula.

Femoral arterial cannulation was then performed in a standard fashion. Venous return was obtained through a $21 \mathrm{~F}$ venous cannula (Medtronic DLP, Grand Rapids, Mich) inserted from the left femoral vein to the right atrium. The position of the venous cannula was checked by means of transesophageal echocardiography. In the event of inadequate venous return, alternative sites of cannulation were used. ${ }^{9} \mathrm{CPB}$ flows, with cardiac indices of up to $2.0 \mathrm{~L} / \mathrm{min}$ per square meter, can be obtained with the carotid artery cannulation. However, concomitant femoral perfusion was used to obtain elevated pump flows, unless a perceived risk of embolization from atherosclerotic plaques or thrombi from the iliofemoral arterial wall and abdominal aortic wall contraindicated its use. CPB was started, and core cooling also was started gradually. After pericardiotomy, a venting cannula was inserted through the left atrial appendage into the left ventricle. During systemic cooling and rewarming, the pump arterial and venous blood tempera- 
tures were monitored, and a difference of no more than $10^{\circ} \mathrm{C}$ between the two was maintained.

The patient's nasopharyngeal, esophageal, and bladder temperatures were monitored. During hypothermic $\mathrm{CPB}$, arterial $\mathrm{pH}$ and $\mathrm{PaCO}_{2}$ were maintained at 7.40 and $40 \mathrm{~mm} \mathrm{Hg}$, respectively, as measured in a blood gas analyzer at $37^{\circ} \mathrm{C}$ (alpha-stat strategy). In preparation for DHCA, steroids were given routinely, and the head was packed in ice to maintain cerebral hypothermia. Systemic cooling was considered to be adequate for hypothermic circulatory arrest when the nasopharyngeal temperature had reached $20^{\circ} \mathrm{C}$ and the bladder temperature was less than $26^{\circ} \mathrm{C}$. At the desired temperature, the table was tilted down, and the systemic arterial flow was then totally arrested. The distal aorta was clamped, and the aneurysm was incised. The common carotid artery was then clamped outside the thorax immediately proximal to the cannulation site, and selective perfusion through the carotid artery was started with a very low flow to allow retrograde washing through the brachiocephalic trunk and left subclavian artery. The left subclavian artery and the brachiocephalic trunk were then clamped as distal as possible from their origin from the arch; alternatively, endoluminal occlusion with a Fogarty catheter was used. Pump flows were raised to indexes of 10 to $15 \mathrm{~mL} \cdot \mathrm{kg}^{-1} \cdot \mathrm{min}^{-1}$, with perfusion pressures not exceeding $80 \mathrm{~mm} \mathrm{Hg}$; perfusion temperatures were maintained at less than $12^{\circ} \mathrm{C}$. The adequacy of intracranial bihemispheric perfusion was assessed by means of TCD scanning. Perfusion pressure was adjusted to obtain right MCA flow velocity within $50 \%$ of the velocity of the left MCA.

Once the proximal anastomosis was completed, careful deairing and purge of debris was performed with the following maneuvers. Central venous pressure was increased, and the left atrial vent was stopped to let the heart and the graft gradually fill with blood. Subsequently, the brachiocephalic trunk clamp was released, allowing a generous retrograde flow toward the arch. The same maneuver was performed with the left subclavian artery. Finally, the left common carotid clamp was released, and proximal perfusion was restarted. Distal anastomosis was performed either with an open technique or with the aid of femoral perfusion.

Decannulation of the left common carotid artery was accomplished by transecting the graft and oversewing the short stump to avoid blind pockets.

\section{Statistical Analysis}

Data of MCA blood flow velocities of the entire patient population and of each of the 2 subgroups, those with an effective collateral blood flow through the anterior communicating artery of the circle of Willis (Willis + ) and those without (Willis -), were analyzed by using routines implemented in FORTRAN by one of the authors (L.B.).

Because of the small-sample setting, distribution-free methods on the basis of permutation inference were used to avoid unrealistic functional assumptions. ${ }^{10}$

A permutation procedure for repeated measures was used to find differences in the mean blood flow velocity for each of the MCAs (right and left) at the 8 time points (T1, basal; T2, left common carotid cannulation; T3, before $\mathrm{CPB}$; T4, normothermic CPB; T5, hypothermic CPB; T6, DHCA with selective cerebral perfusion; T7, total CPB after DHCA; and T8, end of CPB; Table 3 ) and to locate the time points of differences.
By using a permutation procedure on the basis of the paired data, we analyzed the differences between the right and the left MCA mean blood flow velocities for each of the 8 time points (T1-T8) in both the entire patient population and in each of the 2 subgroups (Willis + and Willis-). Moreover, a permutation procedure on the basis of the paired data differences was used to determine the statistical significance to compare the differences between the right and the left MCA mean blood flow velocities for the 2 subgroups.

A further analysis on the basis of data of recorded MCA blood flow velocities during selective cerebral perfusion (T6) at different perfusion pressures was performed to assess the behavior of the 2 subgroups (Willis + and Willis -). The median values of MCA blood flow velocities and their simultaneous confidence intervals were computed by using a permutation procedure.

\section{Results}

\section{Mortality}

None of the patients in this series died during their hospital stay, and there were no late deaths in the postoperative follow-up period.

\section{Morbidity}

All patients awoke from the operation, and none experienced a cerebrovascular accident or paraplegia. In all patients TCD monitoring indicated the absence of cerebral embolic phenomena throughout the entire procedure, including in the presence of concomitant femoral cannulation.

Temporary neurologic dysfunction, as defined by Ergin and associates, ${ }^{11}$ was not observed in any of the patients in this series. There were no complications related to the cannulation technique. Postoperative brain MRI failed to detect any lesion in all patients. None of the patients experienced postoperative paraplegia.

Postoperative hemorrhage requiring repeat operations developed in $2(7.6 \%)$ patients.

The mean intensive care unit stay was $3.1 \pm 2.6$ days, with a mean hospital stay of $11.1 \pm 3.1$ days.

None of the patients experienced late embolic complications in the territory of the left carotid artery.

\section{MCA Flow Velocities}

MCA flow velocities were measured in all patients but one woman because of the absence of a temporal ultrasonic window, and hence the MCA flow velocity data are for 25 patients. Of these, 16 patients had adequate collateral blood flow through the anterior communicating artery of the circle of Willis, as demonstrated with angiography, TCD, or both with compression maneuvers. The changes in both the right and left MCA flow velocity measured by means of TCD throughout the operation are shown in Table 3 (raw data) and in Figures 2 and 3, $A$ and $B$.

A significant effect of time was found, throughout the different time points, in both right and left MCA mean blood flow velocities and in the entire population $(P<$ 
TABLE 3. Physiologic variables and changes in the MCA flow velocity measured by means of TCD throughout the operation (raw data)

\begin{tabular}{|c|c|c|c|c|c|c|c|c|}
\hline & T1 & T2 & T3 & T4 & T5 & T6 & $\mathrm{T} 7$ & T8 \\
\hline $\begin{array}{l}\mathrm{PaCO}_{2} \\
(\mathrm{~mm} \mathrm{Hg})\end{array}$ & $37.6 \pm 7.2$ & $37.4 \pm 6.7$ & $37.8 \pm 5.9$ & $33.1 \pm 3.6$ & $35.1 \pm 3.9$ & $38.3 \pm 4.1$ & $34.2 \pm 4.1$ & $36.8 \pm 5.3$ \\
\hline $\begin{array}{l}\text { Hematocrit (\%) } \\
\text { All patients }\end{array}$ & $35.2 \pm 5.2$ & $35.1 \pm 4.2$ & $35.9 \pm 5.3$ & $24.3 \pm 4.2$ & $22.7 \pm 5.2$ & $22.5 \pm 6.2$ & $23.7 \pm 5.0$ & $29.1 \pm 3.9$ \\
\hline $\begin{array}{l}\text { Mean cerebral } \\
\text { perfusion } \\
\text { pressure } \\
(\mathrm{mm} \mathrm{Hg})\end{array}$ & $76.1 \pm 16.2$ & $78.1 \pm 16.4$ & $75.3 \pm 12.5$ & $56.3 \pm 14.2$ & $49.5 \pm 14.8$ & $59.8 \pm 22.1$ & $47.4 \pm 12.8$ & $66.3 \pm 13.4$ \\
\hline $\begin{array}{l}\text { Right MCA } \\
\text { flow velocity } \\
(\mathrm{cm} / \mathrm{s})\end{array}$ & $43.0 \pm 6.5$ & $43.9 \pm 6.2$ & $43.8 \pm 5.7$ & $59.3 \pm 6.8$ & $33.5 \pm 5.2$ & $26.4 \pm 4.9$ & $35.4 \pm 5.2$ & $46.8 \pm 5.8$ \\
\hline $\begin{array}{l}\text { Left MCA flow } \\
\text { velocity }(\mathrm{cm} / \mathrm{s})\end{array}$ & $43.2 \pm 6.0$ & $40.5 \pm 5.1$ & $42.9 \pm 5.0$ & $60.2 \pm 5.2$ & $34.0 \pm 6.2$ & $34.8 \pm 5.7$ & $36.3 \pm 6.0$ & $45.6 \pm 6.7$ \\
\hline $\begin{array}{l}P \text { value } \\
\% \text { (right/left) }\end{array}$ & $\begin{array}{c}.65 \\
99.5 \pm 4.9\end{array}$ & $\begin{array}{c}<.001 \\
108.7 \pm 11.0\end{array}$ & $\begin{array}{c}.22 \\
102.2 \pm 8.6\end{array}$ & $\begin{array}{c}.84 \\
99.1 \pm 10.4\end{array}$ & $\begin{array}{c}.67 \\
100.1 \pm 16.2\end{array}$ & $\begin{array}{c}<.001 \\
76.0 \pm 8.8\end{array}$ & $\begin{array}{c}.43 \\
99.3 \pm 18.6\end{array}$ & $\begin{array}{c}.54 \\
104.8 \pm 20.4\end{array}$ \\
\hline Willis + & & & & & & & & \\
\hline $\begin{array}{l}\text { Cerebral } \\
\text { perfusion } \\
\text { pressure } \\
(\mathrm{mm} \mathrm{Hg})\end{array}$ & $75.4 \pm 15.1$ & $77.5 \pm 13.7$ & $76.2 \pm 13.5$ & $54.7 \pm 16.2$ & $47.1 \pm 16.8$ & $54.6 \pm 11.1^{*}$ & $45.3 \pm 9.8$ & $59.1 \pm 12.3$ \\
\hline $\begin{array}{l}\text { Right MCA flow } \\
\text { velocity }(\mathrm{cm} / \mathrm{s})\end{array}$ & $43.6 \pm 7.5$ & $44.1 \pm 7.4$ & $44.0 \pm 6.4$ & $57.3 \pm 5.5$ & $33.3 \pm 5.1$ & $27.7 \pm 4.9$ & $34.4 \pm 5.2$ & $48.1 \pm 6.2$ \\
\hline $\begin{array}{l}\text { Left MCA flow } \\
\text { velocity }(\mathrm{cm} / \mathrm{s})\end{array}$ & $43.2 \pm 6.8$ & $40.7 \pm 6.0$ & $42.8 \pm 4.7$ & $59.5 \pm 4.7$ & $32.7 \pm 5.6$ & $34.1 \pm 5.7$ & $34.9 \pm 6.0$ & $45.5 \pm 5.9$ \\
\hline $\begin{array}{l}P \text { value } \\
\% \text { (right/left) }\end{array}$ & $\begin{array}{c}.56 \\
100.9 \pm 5.1\end{array}$ & $\begin{array}{c}.01 \\
100.8 \pm 13.2\end{array}$ & $\begin{array}{c}.09 \\
102.6 \pm 6.3\end{array}$ & $\begin{array}{c}.14 \\
96.6 \pm 9.2\end{array}$ & $\begin{array}{c}.40 \\
100.3 \pm 17.3\end{array}$ & $\begin{array}{c}<.001 \\
81.5 \pm 5.2\end{array}$ & $\begin{array}{c}.79 \\
100.9 \pm 21.8\end{array}$ & $\begin{array}{c}.37 \\
107.7 \pm 21.7\end{array}$ \\
\hline $\begin{array}{l}\text { Cerebral } \\
\text { perfusion } \\
\text { pressure } \\
(\mathrm{mm} \mathrm{Hg})\end{array}$ & $74.1 \pm 15.1$ & $78.7 \pm 9.4$ & $75.6 \pm 12.3$ & $55.4 \pm 13.6$ & $49.2 \pm 13.6$ & $68.4 \pm 14.1^{*}$ & $47.7 \pm 11.4$ & $62.3 \pm 12.9$ \\
\hline $\begin{array}{l}\text { Right MCA flow } \\
\text { velocity }(\mathrm{cm} / \mathrm{s})\end{array}$ & $42.6 \pm 4.3$ & $43.7 \pm 3.5$ & $43.3 \pm 4.5$ & $62.9 \pm 7.6$ & $33.8 \pm 5.5$ & $24.1 \pm 4.3$ & $37.1 \pm 5.0$ & $44.6 \pm 4.4$ \\
\hline $\begin{array}{l}\text { Left MCA flow } \\
\text { velocity }(\mathrm{cm} / \mathrm{s})\end{array}$ & $43.2 \pm 4.7$ & $40.2 \pm 3.2$ & $43.1 \pm 5.8$ & $60.9 \pm 6.2$ & $36.2 \pm 6.7$ & $36.3 \pm 5.8$ & $38.8 \pm 5.4$ & $45.8 \pm 8.4$ \\
\hline $\begin{array}{l}P \text { value } \\
\quad \% \text { (right/left) }\end{array}$ & $\begin{array}{c}.12 \\
99.7 \pm 3.7\end{array}$ & $\begin{array}{c}.01 \\
108.7 \pm 5.6\end{array}$ & $\begin{array}{c}.85 \\
101.5 \pm 12.2\end{array}$ & $\begin{array}{c}.37 \\
103.6 \pm 11.3\end{array}$ & $\begin{array}{c}.13 \\
94.1 \pm 13.0\end{array}$ & $\begin{array}{c}<.001 \\
66.3 \pm 4.3\end{array}$ & $\begin{array}{c}.26 \\
96.6 \pm 12.7\end{array}$ & $\begin{array}{c}.76 \\
99.7 \pm 18.1\end{array}$ \\
\hline
\end{tabular}

Data are expressed as means \pm SD. Time points of the study: $T 1$, basal; T2, left common carotid artery cannulation; T3, before CPB; T4, normothermic CPB; T5, hypothermic CPB; T6, DHCA with selective cerebral perfusion; T7, total CPB after DHCA; T8, end of CPB: Willis +, Effective collateral blood flow through the anterior communicating artery of the Willis circle; Willis -, absent collateral blood flow through the anterior communicating artery of the Willis circle. ${ }^{*} P=.002$.

.001 ), as well as in each subgroup (Willis,$+ P<.001$; Willis,$- P<.001)$.

Significant effects of side and time (side-by-time) differences were found in MCA mean blood flow velocities in the entire population and in each of the 2 subgroups at $\mathrm{T} 2$ and T6 (Table 3).

At the moment of left common carotid artery cannulation (T2), the difference of mean blood flow velocity in the left MCA with respect to the right MCA was significant in both the entire patient population $(P=.001)$ and in each subgroup (Willis,$+ P=.017$; Willis,$- P=.011$ ). There were not significant differences in the decrease of MCA blood flow velocity between the 2 subgroups $(P=.868)$.

At the moment of selective cerebral perfusion (T6), we observed a significant reduction of mean blood flow velocity in the right MCA with respect to the left MCA (all patients, $P<.001$; Willis,$+ P<.001$; Willis,$- P<.001$ ). Significant differences between the 2 subgroups were also observed $(P<.001)$, indicating a more important reduction of flow in patients without effective collateral blood flow through the anterior communicating artery of the circle of Willis (Willis-). 


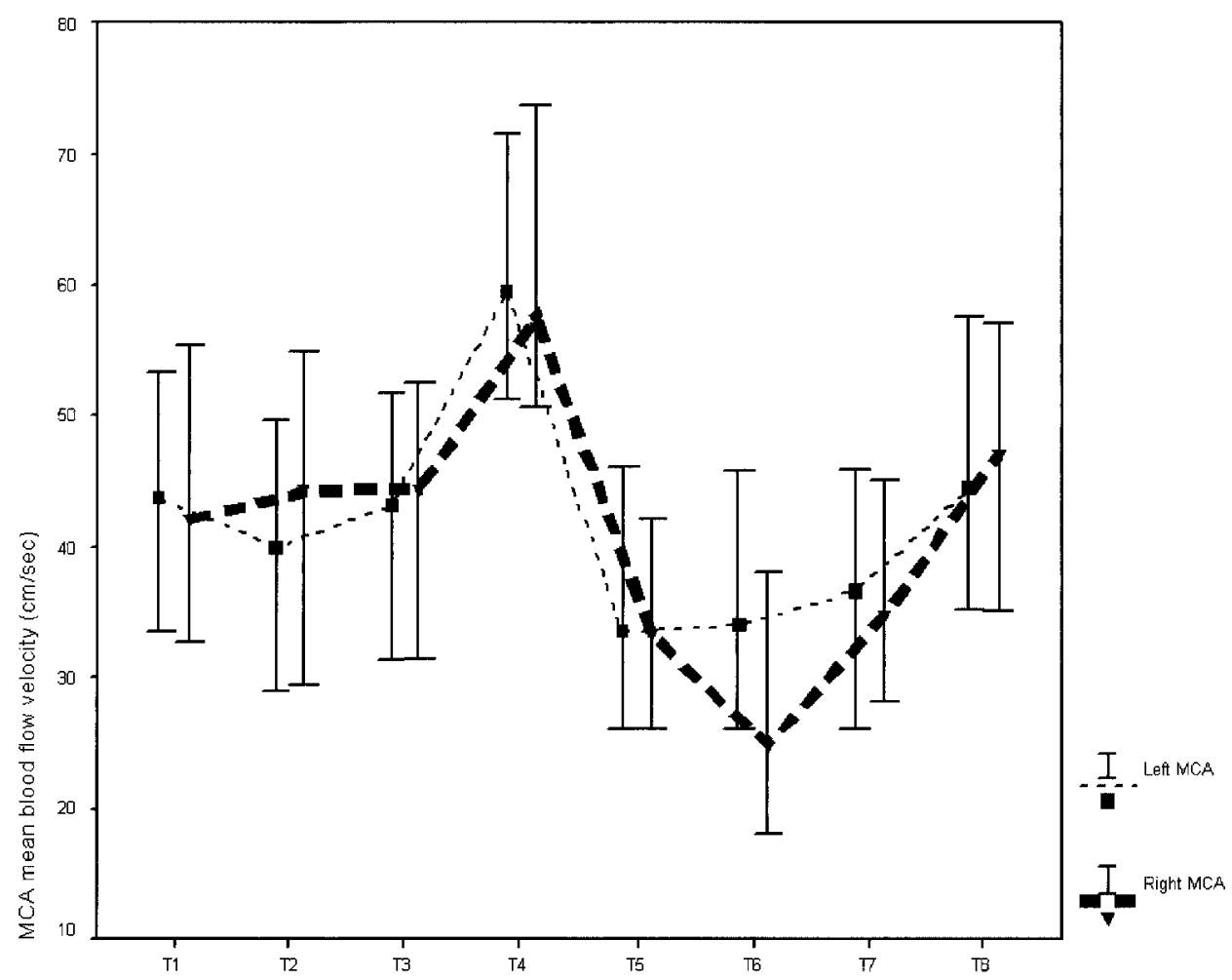

Figure 2. Modifications of MCA mean blood flow velocities at the different time points of the study: bars represent maximum and minimum values, and triangles (right MCA) and squares (left MCA) indicate median values of flow velocity.

At this time point, for the entire population, the relative mean blood velocity in the right MCA with respect to the left MCA was 76.0\% (99\% confidence limit [CL], 69\%$82 \%)$; in the Willis + subgroup the difference was less pronounced, being $81.5 \%$ (99\% CL, 77\%-87\%) compared with that in Willis - patients $66.3 \%$ (99\% CL, 57\%-70\%; Figure 4, $A$ and $B$ ).

The analysis of MCA blood flows recorded during selective cerebral perfusion (T6; Figure 5, $A$ and $B$ ) indicated that the increase of perfusion pressure does not correspond to a linear increase of mean blood flow velocity in the left MCA and that, within the limits of perfusion pressure used in this study, the flow reached a plateau. Moreover, the increase of blood flow velocity observed in the right MCA with the rise of perfusion pressure, obtained by increasing the pump flow, was different between the 2 subgroups.

In patients with an effective collateral blood flow through the anterior communicating artery of the circle of Willis (Willis + ), the rise of perfusion pressure corresponded to an almost parallel increase of the right MCA velocity. In contrast, in patients without an effective collateral blood flow through the circle of Willis (Willis-) the increase of flow was associated with a progressive reduction of the differences between the right and left MCA (Figure 5, $A$ and $B)$.

\section{Discussion}

The open proximal method of operation for complex thoracic aneurysms is thought to be advantageous because it provides a good bloodless operative field and steady anastomosis. ${ }^{12}$ However, the technique, when used for the repair of complex thoracic aortic lesions involving the distal arch, may present major problems, such as a restricted time of circulatory arrest to the brain and difficulties in deairing from the arch branches and proximal ascending aorta.

In their series Ergin and associates ${ }^{11}$ reported that strokes caused by emboli occurred in $11.8 \%$ of patients who had undergone an aortic arch repair during hypothermic circulatory arrest. They observed, furthermore, that the prevalence of stroke was higher in patients with descending aorta and distal arch replacement than in those with total arch replacement. Okita and associates ${ }^{13}$ reported 148 aortic arch operations with retrograde cerebral perfusion and found that stroke occurred in $7 \%$ of patients undergoing the procedure by way of a left thoracotomy and in only $2 \%$ of patients undergoing the procedure by way of a median sternotomy.

Dossche and coworkers, ${ }^{14}$ in their series of aortic arch operations performed with the aid of antegrade selective cerebral perfusion (ASCP), found that when a midline sternotomy was not used, the risk of perioperative central neurologic damage was increased. 


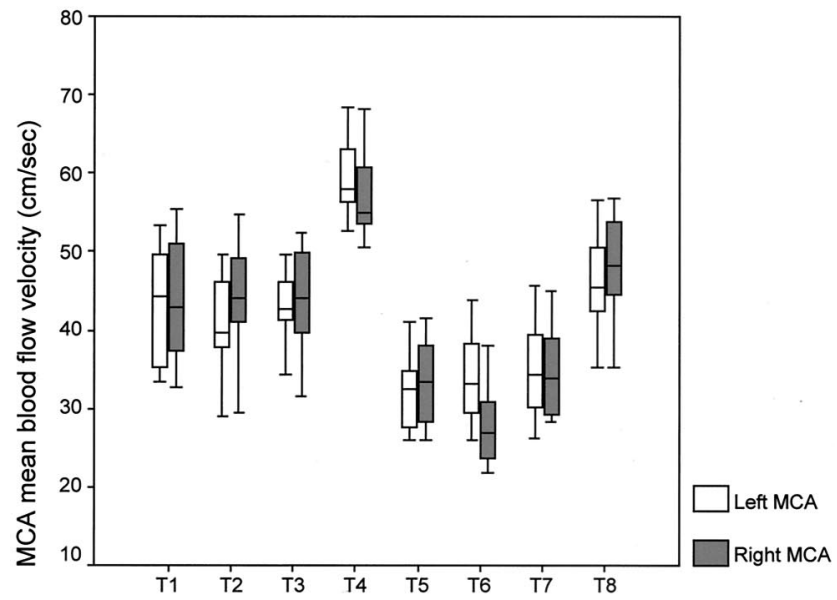

A Willis +

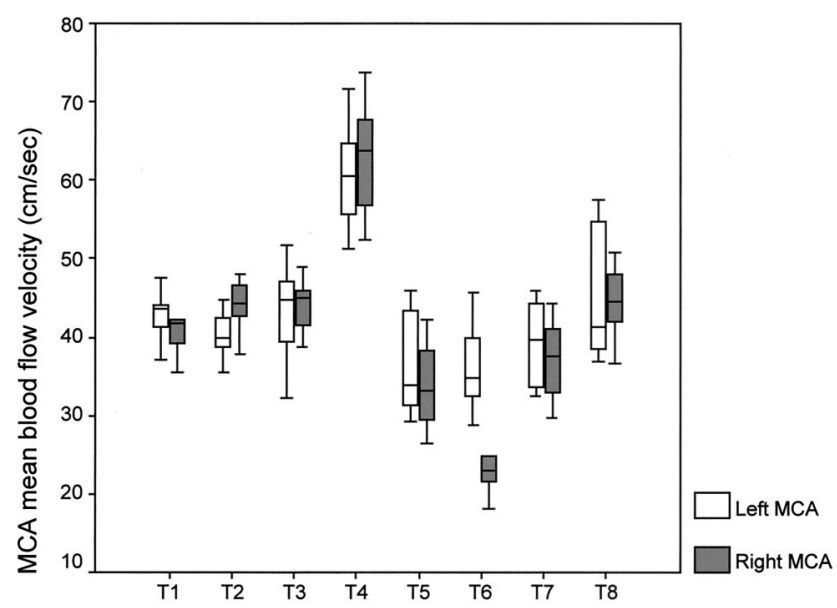

B Willis-

Figure 3. Box plots represent the distribution of mean blood flow velocities in both the right and left MCA at the different time points of the study in patients with adequate collateral circulation through the anterior communicating artery of the circle of Willis (Willis +, A) and in patients with absent collateral circulation through the anterior communicating artery of the circle of Willis (Willis-, B).

Central aortic cannulation is less likely to cause these problems, and therefore an assortment of approaches have been proposed to obtain central perfusion through a posterolateral thoracotomy. These include right axillary cannulation, ${ }^{15}$ intrathoracic left axillary artery cannulation, ${ }^{16}$ apicoventricular cannulation, ${ }^{17}$ and extended thoracotomy with cannulation of the ascending aorta. ${ }^{18}$

ASCP and retrograde cerebral perfusion ${ }^{19,20}$ are used to increase the time of safe hypothermic circulatory arrest and to protect the central nervous system from ischemia and embolism during operations on the distal aortic arch. However, both methods have some disadvantages. The isolation

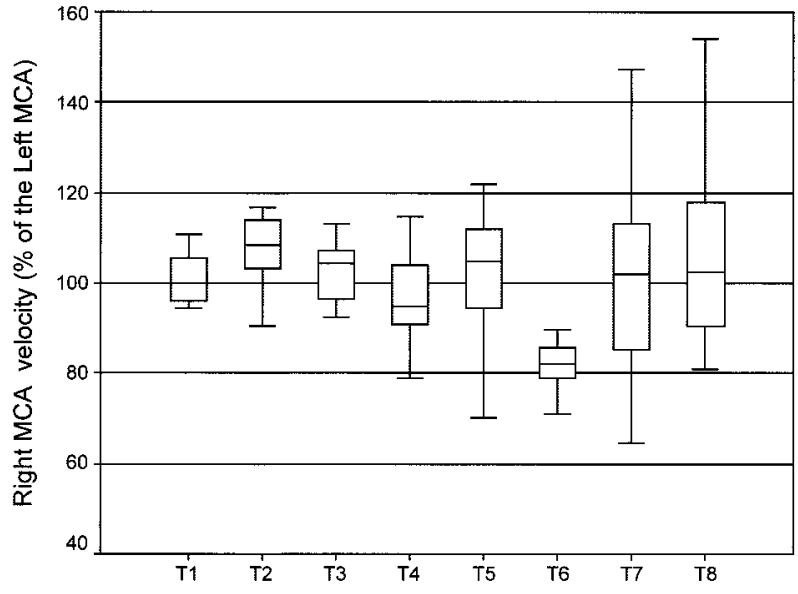

A Willis +

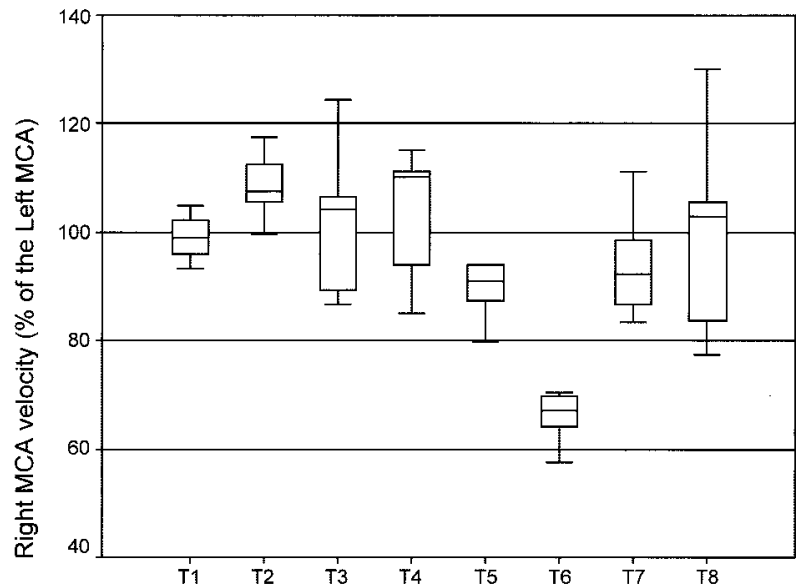

B Willis -

Figure 4. Relative flow velocity of the right MCA expressed as a percentage of the left MCA at the different time points of the study in patients with adequate collateral circulation through the anterior communicating artery of the circle of Willis (Willis +, A) and in patients with absent collateral circulation through the anterior communicating artery of the circle of Willis (Willis-, B).

of the aortic arch vessels and installation of ASCP catheters through a posterolateral thoracotomy requires more manipulation of the aortic arch or descending aorta than through a midline sternotomy, thus enhancing the risk of embolization of atheromatous debris. The procedure is also associated with the danger of inadequate deairing of the ASCP catheters. ${ }^{14}$

The beneficial mechanism of action of retrograde cerebral perfusion is still a matter of intense debate. The analysis of clinical results has shown that long durations of retrograde cerebral perfusion are associated not only with high rates of temporary neurologic dysfunction but also, in some studies, with an increased risk of stroke and death after aortic surgery. ${ }^{21}$ 
Extrathoracic left common carotid cannulation combines the advantages of central aortic cannulation with those of the selective cerebral perfusion. It spares extended thoracic incisions, avoids the cannulation of fragile structures, and decreases the risk of bleeding or dissection of the aorta at the cannulation site.

During the cooling and rewarming phases, the procedure proposed in the present study provides a reliable proximal perfusion, creating a flow that diverts particulate emboli and air from the cerebral vessel and avoids cerebral malperfusion in aortic dissection. For these reasons, it can be safely used in combination with femoral arterial perfusion.

In surgical procedures for ruptured thoracic aneurysms, left common carotid artery cannulation enables perfusion of the vital organs proximal to the ruptured area and thus maintains a blood supply to the brain, even if the heart is stopped and profound hypothermia is not attained.

Cerebral perfusion through a single vessel can be a matter of concern because the effectiveness of a collateral circulation through the anterior communicating cerebral artery of the circle of Willis may greatly influence the blood supply of both hemispheres.

TCD insonation permits a quantitative and noninvasive evaluation of intracerebral arterial velocity. TCD is a reliable tool in identifying significant collateral arteries ${ }^{6}$ and provides a clearer understanding of the effects of selective cerebral perfusion on cerebral blood flow during surgical intervention.

Intraoperative TCD monitoring immediately detects induced changes in MCA blood velocity, which have been demonstrated to correlate with stump pressure and electroencephalographic changes. ${ }^{6}$ From the experience of carotid artery surgery, 2 types of criteria have been defined for indicating which patients should be selectively shunted. ${ }^{22}$ These are a specified drop (of either $50 \%$ or $60 \%$ ) in MCA velocity after internal carotid artery clamping and after clamping a fall in the MCA velocity of less than $15 \mathrm{~cm} / \mathrm{s}^{23}$

In the present study the results of TCD monitoring confirmed that a significant reduction of blood flow velocity occurred at the moment of selective perfusion through the left common carotid artery and that this decrease was more pronounced in patients without a demonstrable anterior communicating cerebral artery. Despite this, an increase of perfusion pressures in the left common carotid artery enabled the flow in the right hemisphere to be augmented, thus maintaining the right MCA blood flow velocity within $50 \%$ of the contralateral artery and greater than $15 \mathrm{~cm} / \mathrm{s}$. This indicated that the recruitment of a collateral circulation reduced the flow differences between the right and left systems. Adequate flow in the right MCA was thus achieved while maintaining physiologic pressure levels in the left MCA, with a lowered danger of cerebral edema.

The rich network of anastomoses interconnecting the cervical, vertebral, occipital, and carotid arteries, commonly

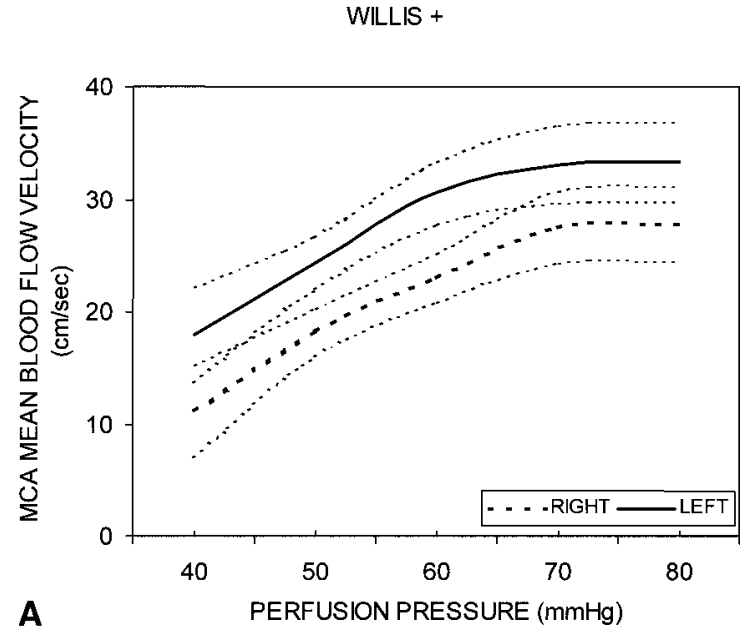

WILLIS -

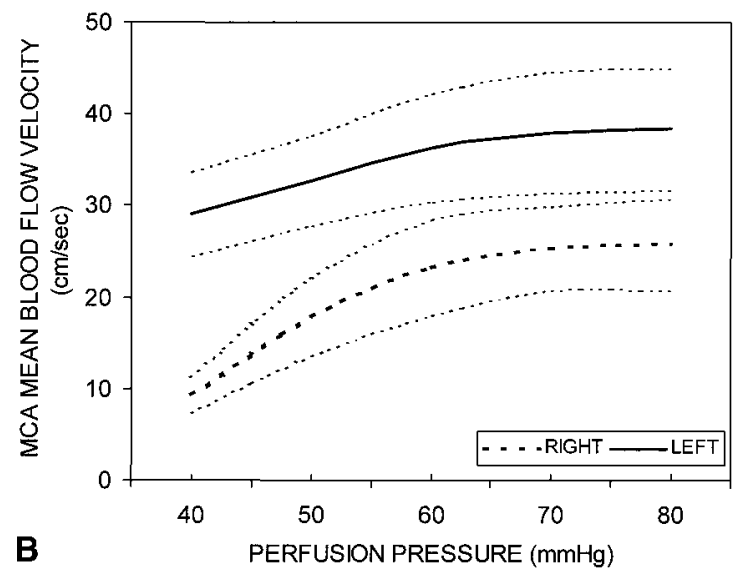

Figure 5. Lines represent the medians (thick lines) and the $95 \%$ CLs of both the right and left MCA blood flow velocities at different perfusion pressures during selective cerebral perfusion (T6) in patients with adequate collateral circulation through the anterior communicating artery of the circle of Willis (Willis +, A) and in patients with absent collateral circulation through the anterior communicating artery of the circle of Willis (Willis-, B).

designated as suboccipital carrefour or knot, represents the anatomic basis of this recruitment process. ${ }^{24}$

The generous retrograde blood flow from the left subclavian artery and from the brachiocephalic trunk that can be observed from inside of the aorta when clamps are released confirms de visu the adequacy of these collaterals, with regard also to the posterior circulation.

In summary, the present data have indicated that cannulation and perfusion of the left common carotid artery enabled cerebral blood flow that could prolong the time of safe circulatory arrest. At this stage, however, our findings suggest that such cannulation procedures for arch operations should only be used with the protection of profound hypothermia. 
We thank Mr Massimo Gistri del Nicchio for his technical assistance for TCD measurements. We thank the surgical and nursing staff of the Cardiovascular Surgery Unit at Siena University Hospital.

\section{References}

1. Crawford ES, Coselli JS, Safi HJ. Partial cardiopulmonary bypass, hypothermic circulatory arrest, and posterolateral exposure for thoracic aortic aneurysm operation. J Thorac Cardiovasc Surg. 1987;94:824-7.

2. Kouchoukos NT, Daily BB, Rokkas CK, Murphy SF, Bauer S, Abboud N. Hypothermic bypass and circulatory arrest for operations on the descending thoracic and thoracoabdominal aorta. Ann Thorac Surg. 1995;60:67-76.

3. Sabik JF, Lytle BW, McCarthy PM, Cosgrove DM. Axillary artery. J Thorac Cardiovasc Surg. 1995;109:885-91.

4. Colleti G, Torracca L, Canna GL, et al. Diagnosis and management of cerebral malperfusion phenomena during aortic dissection repair by transesophageal doppler echocardiographic examination. J Card Surg. 1996;11:355-8.

5. Bichell DP, Balaguer JM, Aranki SF, et al. Axilloaxillary cardiopulmonary bypass. Ann Thorac Surg. 1997;64:702-5.

6. Schneider PA, Rossman ME, Torem S, Otis SM, Dilley RB, Bernstein EF. Transcranial Doppler in the management of extracranial cerebrovascular disease. Implications in diagnosis and monitoring. $J$ Vasc Surg. 1988;7:223-31.

7. Aaslid R, Markwalder TM, Nornes H. Noninvasive transcranial Doppler ultrasound recording of velocity in basal cerebral arteries. $J$ Neurosurg. 1982;57:769-74.

8. Spencer MP, Thomas GI, Nicholls SC, Sauvage LR. Detection of middle cerebral artery emboli during carotid endarterectomy using transcranial Doppler ultrasonography. Stroke. 1990;21:415-23.

9. Neri E, Maiza D, Coffin O, Massetti M. Transpericardial inferior vena caval cannulation in thoracic aorta operations. Ann Thorac Surg. 1996;62:1208-9.

10. Pesarin F. Permutation testing for repeated measurements. In: Pesarin F, editor. Multivariate permutation tests with applications in Biostatistics. 1st ed. New York: John Wiley; 2001.

11. Ergin MA, Galla JD, Lansman sL, Quintana C, Bodian C, Griepp RB. Hypothermic circulatory arrest in operations on the thoracic aorta. Determinants of operative mortality and neurologic outcome. J Thorac Cardiovasc Surg. 1994;107:788-97.
12. Szentpetery S, Crisler C, Grinnan GLB. Deep hypothermic arrest and left thoracotomy for repair of difficult thoracic aneurysms. Ann Thorac Surg. 1993;55:830-3.

13. Okita Y, Takamoto S, Ando M, Morota T, Matsukawa R, Kawashima Y. Mortality and cerebral outcome in patients who underwent aortic arch operations using deep hypothermic circulatory arrest with retrograde cerebral perfusion. J Thorac Cardiovasc Surg. 1998;115:129-38.

14. Dossche KM, Morshuis WJ, Schepens MA, Waanders FG. Bilateral antegrade selective cerebral perfusion during surgery on the proximal thoracic aorta. Eur J Cardiothorac Surg. 2000;17:462-7.

15. Katoh T, Gohra H, Hamano K, Takenaka H, Zempo N, Esato K. Right axillary cannulation in the left thoracotomy for thoracic aortic aneurysm. Ann Thorac Surg. 2000;70:311-3.

16. Moriyama Y, Iguro Y, Hisatomi K, Yotsumoto G, Yamamoto H, Toda R. Thoracic and thoracoabdominal aneurysm repair under deep hypothermia using subclavian arterial perfusion. Ann Thorac Surg. 2001; 71:29-32.

17. Shiiya N, Yasuda K, Murashita T, et al. Transapical aortic cannulation for hypothermic aortic operation through a left thoracotomy: an alternative to avoid retrograde arterial perfusion. J Thorac Cardiovasc Surg. 1997;113:1113-4

18. Westaby S, Katsumata T. Proximal aortic perfusion for complex arch and descending aortic disease. J Thorac Cardiovasc Surg. 1998;115:162-7.

19. Yasuura K, Takagi Y, Oohara Y, Takami Y. Total body retrograde perfusion during operations on the descending thoracic aorta. J Thorac Cardiovasc Surg. 1999;118:559-61.

20. Takamoto S, Okita Y, Ando M, Morota T, Handa N, Kawashima Y Retrograde cerebral circulation for distal aortic arch surgery through a left thoracotomy. J Card Surg. 1994;9:576-83.

21. Griepp RB. Cerebral protection during aortic arch surgery. J Thorac Cardiovasc Surg. 2001;121:425-7.

22. Hayes PD, Vainas T, Hartley S, et al. The Pruitt-Inahara shunt maintains mean middle cerebral artery velocities within $10 \%$ of preoperative values during carotid endarterectomy. J Vasc Surg. 2000;32:299-306.

23. Halsey JH, McDowell HA, Gelmon S, Morawetz RB. Blood velocity in the middle cerebral artery and regional cerebral blood flow during CEA. Stroke. 1989;20:53-8.

24. Ayad M, Vinuela F, Rubinstein EH. The suboccipital carrefour: cervical and vertebral arterial anastomosis. AJNR Am J Neuroradiol. 1998;19:925-31.

\section{Targeted}

The Journal of Thoracic and Cardiovascular Surgery gives you two tables of contents.

The condensed table of contents tells you at a glance what topics and authors are presented each month. The expanded table of contents gives you a brief abstract of each article. You select only those articles of most interest to you for further reading. 